\title{
TRATAMENTOS PRÉ-GERMINATIVOS EM SEMENTES DE MAMONA (Ricinus communis L.) ${ }^{1}$
}

\author{
RITA DE CÁSSIA MENDES²; DENISE CUNHA FERNANDES DOS SANTOS DIAS; \\ MARCIO DIAS PEREIRA2; PAULO GERALDO BERGER ${ }^{3}$
}

\begin{abstract}
RESUMO - As sementes de mamona têm germinação lenta e irregular, resultando, muitas vezes, em estande desuniforme no campo, o que pode ser atribuído à provável dificuldade de absorção de água pelas sementes. $\mathrm{O}$ trabalho teve como objetivo avaliar o efeito de tratamentos pré-germinativos no desempenho de sementes de mamona. Foram utilizados cinco lotes de sementes de mamona, cultivar AL-Guarany, que foram submetidos aos seguintes tratamentos: testemunha (sementes intactas), escarificação com lixa, remoção da carúncula, remoção do tegumento, imersão em água por 12 e 24 horas, remoção da carúncula + imersão em água por 12 e 24 horas, escarificação com lixa + imersão em água por 12 e 24 horas, germinação a $10^{\circ} \mathrm{C} / 7$ dias e a $25^{\circ} \mathrm{C} / 5$ dias, germinação a $10^{\circ} \mathrm{C} / 7$ dias e a $30^{\circ} \mathrm{C} / 5$ dias e envelhecimento acelerado a $41^{\circ} \mathrm{C} / 48 \mathrm{~h}$ e $100 \%$ UR. Após cada tratamento, com exceção dos tratamentos de germinação a $10^{\circ} \mathrm{C}$, as sementes foram submetidas ao teste de germinação, a $25^{\circ} \mathrm{C}$, avaliando-se a porcentagem de plântulas normais aos sete e 14 dias após a semeadura. Em geral, todos os tratamentos pré-germinativos contribuíram para aumentar a porcentagem de germinação das sementes de mamona em relação à testemunha. Os tratamentos mais eficientes para acelerar a germinação das sementes foram a escarificação com lixa e a remoção da carúncula ou de todo o tegumento. No entanto, considerando a praticidade de aplicação, a escarificação com lixa pode ser recomendada para acelerar e aumentar a germinação das sementes de mamona.
\end{abstract}

Termos para indexação: Ricinus communis L., velocidade de germinação, escarificação.

\section{PRE-GERMINATIVE TREATMENTS IN CASTOR BEAN (Ricinus communis L.) SEEDS}

\begin{abstract}
Castor bean seeds have slow and irregular germination that frequently results in irregular seedling emergence in the field. This fact has been attributed to their probable impermeability to water. The objective of this study was to evaluate the effect of pre-germination treatments on seed performance. Five seed lots, AL-Guarany cultivar, were submitted to the following treatments: control (untreated seeds), scarification with sandpaper, caruncle removal, tegument removal, immersion in water for 12 and 24h, caruncle removal + immersion in water for 12 and 24h, scarification with sandpaper + immersion in water for 12 and $24 \mathrm{~h}$, germination at $10^{\circ} \mathrm{C} / 7$ days and at $25^{\circ} \mathrm{C} / 5$ days, germination at $10^{\circ} \mathrm{C} / 7$ days and at $30^{\circ} \mathrm{C} / 5$ days, accelerated aging at $41^{\circ} \mathrm{C} / 48 \mathrm{~h}$ and $100 \% \mathrm{RH}$. After each treatment, with exception of the germination at $10^{\circ} \mathrm{C}$, the seeds were submitted to the germination test, at $25^{\circ} \mathrm{C}$. Counts were performed at 7 and 14 days after sowing. In general, all the pre-germination
\end{abstract}

${ }^{1}$ Submetido em 26/05/2008. Aceito para publicação em 19/11/2008. Parte da dissertação da primeira autora, apresentada ao Programa de Pós-Graduação em Fitotecnia da Universidade Federal de Viçosa - UFV.

${ }^{2}$ Eng. Agr., M.S. em Fitotecnia, Depto. de Fitotecnia, UFV, 36570-000 -
Viçosa-MG.

${ }^{3}$ Eng. Agr. Dr. Prof. Associado, Departamento de Fitotecnia, UFV, 36570000 - Viçosa - MG. Bolsista CNPq. E-mail: dcdias@ufv.br 
treatments contributed to increasing the germination percentage of castor bean seeds in relation to the control. The most efficient treatments to speed up germination were scarification with sandpaper and caruncle or tegument removal. However, considering the practical application, scarification can be recommended to increase the percentage and speed of seed germination.

Index terms: Ricinus communis L., speed of germination, scarification.

\section{INTRODUÇÃO}

A mamona (Ricinus communis L.) é uma planta da família Euphorbiaceae, cujo óleo extraído de suas sementes é solúvel em álcool com inúmeras aplicações na indústria, sendo usado na fabricação de plásticos, fibras sintéticas, tintas, esmaltes, entre outros (Fonseca et al., 2004). As características deste óleo têm despertado interesse também como uma alternativa promissora para a produção de biodiesel, um combustível biodegradável, renovável e ecologicamente correto.

Considerada uma planta rústica, as variedades de mamona selecionadas para o cultivo apresentam, em geral, sementes com germinação lenta e desuniforme (Oliveira et al., 2004), ficando por mais tempo expostas aos patógenos de solo e às intempéries, o que resulta em estande final irregular. Segundo Oliveira et al. (2004), a germinação lenta e irregular representa uma desvantagem na competição inicial com plantas invasoras e vulnerabilidade à estiagem durante a emergência em campo, que pode chegar a 20 dias, nas principais regiões produtoras. Portanto, emergência rápida e uniforme é importante, visto que permite a obtenção de estandes adequados, com plantas bem desenvolvidas, o que facilitará, posteriormente, o manejo durante a colheita e processamento, com reflexos positivos na produtividade da lavoura e no rendimento de óleo.

A irregularidade na emergência das plântulas de mamona em campo e também em laboratório tem sido atribuída à dificuldade de absorção de água pelas sementes, devido à espessura e rigidez do tegumento ou a uma possível dormência pós-colheita (Lago et al., 1979), representada pela dureza tegumentar. Estes autores, ao avaliarem a qualidade fisiológica de sementes de mamona, cultivares Guarani e IAC38 , constataram variação de 9 a $66 \%$ de sementes dormentes. Sabe-se que a água é o fator que mais influencia o processo de germinação, sendo responsável pelo início da hidratação dos tecidos das sementes, e, com isso, pela intensificação da respiração e de todos os processos metabólicos necessários para a digestão e mobilização de reservas, que resultam na retomada do crescimento do eixo embrionário e formação da plântula (Bewley e Black, 1994).

Plantas de pelo menos quinze famílias economicamente importantes, com destaque para a família Fabaceae, produzem sementes com tegumento temporariamente impermeável à água. Tais sementes apresentam um mecanismo físico de dormência, denominada dureza tegumentar, que provoca germinação irregular, comprometendo o estabelecimento do estande, gerando desenvolvimento e maturação desuniforme das plantas, além de reduzir o potencial de competição das plantas cultivadas com as invasoras (Marcos Filho, 2005).

Em laboratório, diversos procedimentos podem ser empregados para a superação da dureza tegumentar das sementes de espécies que apresentam tal característica, entre os quais pode se destacar a escarificação mecânica, a escarificação química, a imersão em água, aquecida ou a temperatura ambiente, por determinado período de tempo, punção, corte ou até a retirada parcial ou completa do tegumento (Brasil, 1992). O choque térmico, representado por alternância ou flutuações de temperatura, também pode contribuir para promover alterações no envoltório das sementes, sendo que a amplitude das flutuações deve ser superior a $15^{\circ} \mathrm{C}$ (Perez, 2004). Em sementes com tegumento espesso também se pode empregar o calor úmido para auxiliar o processo de hidratação, como em canafístula (Peltophorum dubium), onde a exposição das sementes à temperatura de $45^{\circ} \mathrm{C}$ e $100 \%$ de umidade relativa, por 24 a 48 horas, promoveu o amolecimento do tegumento (Perez et al., 1999). Tais condições correspondem àquelas recomendadas para a condução do teste de envelhecimento acelerado, utilizado para a avaliação do vigor de sementes (Marcos Filho, 1999). Contudo, a aplicação e a eficiência desses tratamentos dependem, principalmente, do grau de dureza, o que é bastante variável entre as espécies (Lima e Garcia, 1996) e também entre genótipos e lotes da mesma espécie.

A escarificação mecânica geralmente é feita com o auxílio de lixas, mas pode-se utilizar também tratamentos de punção do tegumento, retirada de carúncula, cortes ao longo 
do tegumento, na região da micrópila ou em região oposta a esta, sendo a maioria dos estudos realizados em sementes de leguminosas. Tais tratamentos têm sido recomendados para a superação da dureza tegumentar de sementes, principalmente para leguminosas (Brasil, 1992; Perez, 2004).

Em mamona, Oliveira et al. (2004) embeberam sementes intactas e sem carúncula em água por $0,4,8$ e 12 horas, utilizando sementes recém-colhidas e com 10 meses de idade. Verificaram que a remoção da carúncula teve efeito significativo acelerando a germinação, especialmente das sementes embebidas em água por quatro horas. Já a embebição em água, por oito horas, das sementes recémcolhidas provocou atraso na germinação. Também Queiroz et al. (2004) constataram que a remoção da carúncula contribuiu para acelerar a germinação das sementes recémcolhidas tendo efeito positivo sobre o crescimento inicial das plântulas. Por sua vez, Lucena et al. (2004) embeberam as sementes de mamona em soluções de $\mathrm{GA}_{3}$ a 0, 200, 400, 600 e 800 ppm antes da semeadura, não constatando efeito deste hormônio na porcentagem de germinação nem no tempo necessário para se obterem $50 \%$ de sementes germinadas.

Contudo, as informações existentes na literatura referentes a métodos adequados para acelerar a germinação e romper a dureza do tegumento das sementes de mamona devem ser interpretadas com cuidado, pois existe grande diversidade de materiais utilizados nos plantios comerciais, desde os mais rústicos até variedades melhoradas, cujo potencial germinativo e nível de dureza tegumentar das sementes são bastante variáveis.

Diante do exposto, o presente trabalho teve como objetivo avaliar a eficiência de tratamentos pré-germinativos no desempenho de sementes de mamona.

\section{MATERIAL E MÉTODOS}

O trabalho foi realizado no Laboratório de Análises de Sementes do Departamento de Fitotecnia da Universidade Federal de Viçosa no período de fevereiro a julho de 2007. Utilizaram-se cinco lotes comerciais de sementes de mamona, da cultivar AL-Guarany, adquiridos da CATI - SP, logo após a colheita e apresentando teor de água entre $6,4 \%$ e $7,2 \%$, determinado pelo método da estufa a $105 \pm 3^{\circ} \mathrm{C}$ por 24 horas (Brasil, 1992). As sementes de cada lote foram submetidas aos seguintes tratamentos pré-germinativos:

Testemunha: sementes intactas

Escarificação do tegumento com lixa: utilizando-se uma lixa d'água no 1 efetuou-se a escarificação do tegumento, friccionando-se na lixa a região da semente oposta à carúncula até que a parte interna ao tegumento (endosperma) fosse exposta.

Remoção da carúncula: a carúncula de cada semente foi removida com o auxilio de um estilete, deixando-se a micrópila exposta.

Remoção do tegumento: com o auxilio de um estilete retirou-se o tegumento coriáceo das sementes, deixando exposto o endosperma que envolve o embrião.

Imersão em água: 200 sementes intactas foram imersas em $500 \mathrm{~mL}$ de água destilada, por 12 e 24 horas, em ambiente de laboratório, a $25^{\circ} \mathrm{C}$.

Remoção da carúncula + imersão em água: 200 sementes cuja carúncula foi removida foram imersas em $500 \mathrm{~mL}$ de água destilada, por 12 e 24 horas, em ambiente de laboratório $\left(25^{\circ} \mathrm{C}\right)$.

Escarificação com lixa + imersão em água: 200 sementes submetidas à escarificação com lixa foram imersas em $500 \mathrm{~mL}$ de água destilada, por 12 e 24 horas, em temperatura ambiente de laboratório $\left(25^{\circ} \mathrm{C}\right)$.

Envelhecimento acelerado: realizado conforme Marcos Filho (1999) com quatro repetições de 50 sementes, que foram distribuídas em camada única sobre bandeja de tela metálica acoplada em caixas plásticas tipo gerbox, que funcionam como compartimento individual (mini-câmaras). Cada gerbox continha, ao fundo, $40 \mathrm{~mL}$ de água. Os gerbox foram tampados, de modo a obter cerca de $100 \%$ de UR em seu interior e foram mantidos em incubadora BOD a $41^{\circ} \mathrm{C}$, durante 48 horas.

As sementes de cada tratamento descrito acima foram submetidas ao teste de germinação, utilizando-se quatro repetições de 50 sementes que foram distribuídas em papel toalha umedecido com volume de água equivalente a 3,0 vezes a massa do papel seco. Foram confeccionados rolos, que foram mantidos em germinador à temperatura de $25^{\circ} \mathrm{C}$, realizando-se contagens aos sete (primeira contagem de germinação) e 14 dias após a semeadura, de acordo com as Regras para Análise de Sementes - RAS (Brasil, 1992). Os resultados foram expressos em porcentagem de plântulas normais obtidas aos sete e 14 dias. Para as sementes submetidas ao envelhecimento acelerado foi feita uma única avaliação aos sete dias após a semeadura.

Além dos tratamentos descritos acima, foram aplicados também os seguintes tratamentos:

Germinação a $10^{\circ} \mathrm{C} / \mathbf{2 5}^{\circ} \mathrm{C}$ : quatro repetições de 50 sementes foram distribuídas entre folhas de papel toalha umedecidas com quantidade de água equivalente a 3,0 vezes a massa do substrato seco. Foram preparados rolos 
que foram colocados no interior de sacos plásticos vedados com fita crepe (para reduzir a evaporação) e mantidos em incubadora $\mathrm{BOD}$, a $10^{\circ} \mathrm{C}$, por sete dias. Após este período, os rolos foram transferidos para um germinador a $25^{\circ} \mathrm{C}$, onde permaneceram por cinco dias, quando foram realizadas as avaliações, calculando-se a porcentagem de plântulas normais.

Germinação a $10^{\circ} \mathrm{C} / 30^{\circ} \mathrm{C}$ : seguiu-se a metodologia descrita para a germinação a $10^{\circ} \mathrm{C} / 25^{\circ} \mathrm{C}$, transferindo-se os rolos que permaneceram a $10^{\circ} \mathrm{C}$ para um germinador regulado a $30^{\circ} \mathrm{C}$.

$\mathrm{O}$ delineamento experimental empregado foi $\mathrm{o}$ inteiramente casualizado com quatro repetições. Os dados obtidos para cada lote e tratamento foram submetidos a analise de variância empregando-se o programa de análise estatística SAS (1989). As médias dos tratamentos foram comparadas pelo teste de Tukey $(\mathrm{p}<0,05)$.

\section{RESULTADOS E DISCUSSÃO}

As sementes de mamona que não foram submetidas aos tratamentos pré-germinativos (testemunha) apresentaram germinação entre 59 e $78 \%$ (Tabela 1), valores estes abaixo do padrão estabelecido para a comercialização de sementes desta espécie no Brasil que é de $80 \%$ (DFASP, 2007). Notase ainda a presença de sementes duras em todos os lotes (Tabela 2), com valores variando entre $15 \%$ (lote 4) e $25 \%$ (lote 5). Com a aplicação dos tratamentos pré-germinativos, observa-se, para todos os lotes, que, em geral, houve aumento significativo na germinação em relação à testemunha, devido à redução da ocorrência de sementes duras.

TABELA 1. Germinação (\%) de sementes de cinco lotes de mamona submetidas a diferentes tratamentos prégerminativos.

\begin{tabular}{|c|c|c|c|c|c|c|}
\hline & Lote 1 & Lote 2 & Lote 3 & Lote 4 & Lote 5 & Média \\
\hline Sementes intactas (testemunha) & $74 \mathrm{C}$ & $66 \mathrm{C}$ & $74 \mathrm{C}$ & $78 \mathrm{C}$ & $59 \mathrm{D}$ & 70 \\
\hline Escarificação com lixa & $93 \mathrm{AB}$ & $80 \mathrm{AB}$ & $93 \mathrm{~A}$ & $94 \mathrm{AB}$ & $80 \mathrm{~B}$ & 88 \\
\hline Remoção da carúncula & $94 \mathrm{AB}$ & $83 \mathrm{AB}$ & $90 \mathrm{AB}$ & $93 \mathrm{AB}$ & $88 \mathrm{~A}$ & 90 \\
\hline Remoção do tegumento & $95 \mathrm{AB}$ & $83 \mathrm{AB}$ & $90 \mathrm{AB}$ & $91 \mathrm{AB}$ & $86 \mathrm{AB}$ & 89 \\
\hline Imersão em água por $12 \mathrm{~h}$ & $89 \mathrm{~B}$ & $86 \mathrm{AB}$ & $84 \mathrm{~B}$ & $81 \mathrm{BC}$ & $79 \mathrm{~B}$ & 84 \\
\hline $\begin{array}{l}\text { Remoção da carúncula + imersão em } \\
\text { água por } 12 \mathrm{~h}\end{array}$ & $93 \mathrm{AB}$ & $79 \mathrm{~B}$ & $87 \mathrm{AB}$ & $88 \mathrm{AB}$ & $83 \mathrm{AB}$ & 86 \\
\hline $\begin{array}{l}\text { Escarificação com lixa + imersão em } \\
\text { água por } 12 \mathrm{~h}\end{array}$ & $96 \mathrm{AB}$ & $86 \mathrm{AB}$ & $88 \mathrm{AB}$ & $92 \mathrm{AB}$ & $81 \mathrm{AB}$ & 89 \\
\hline Imersão em água por $24 \mathrm{~h}$ & $86 \mathrm{~B}$ & $87 \mathrm{~A}$ & $87 \mathrm{AB}$ & $88 \mathrm{AB}$ & $71 \mathrm{C}$ & 84 \\
\hline $\begin{array}{l}\text { Remoção da carúncula + imersão em } \\
\text { água por } 24 \mathrm{~h}\end{array}$ & $92 \mathrm{AB}$ & $83 \mathrm{AB}$ & $84 \mathrm{~B}$ & $84 \mathrm{BC}$ & $79 \mathrm{~B}$ & 84 \\
\hline $\begin{array}{l}\text { Escarificação com lixa + imersão em } \\
\text { água por } 24 \mathrm{~h}\end{array}$ & $99 \mathrm{~A}$ & $80 \mathrm{AB}$ & $87 \mathrm{AB}$ & $87 \mathrm{~B}$ & $79 \mathrm{~B}$ & 86 \\
\hline Germinação a $10^{\circ} \mathrm{C} / 25^{\circ} \mathrm{C}$ & $93 \mathrm{AB}$ & $85 \mathrm{AB}$ & $86 \mathrm{AB}$ & $95 \mathrm{~A}$ & $83 \mathrm{AB}$ & 88 \\
\hline Germinação a $10^{\circ} \mathrm{C} / 30^{\circ} \mathrm{C}$ & $87 \mathrm{~B}$ & $72 \mathrm{~B}$ & $81 \mathrm{BC}$ & $91 \mathrm{AB}$ & $82 \mathrm{AB}$ & 83 \\
\hline Envelhecimento acelerado & $88 \mathrm{~B}$ & $82 \mathrm{~B}$ & $84 \mathrm{~B}$ & $82 \mathrm{BC}$ & $70 \mathrm{C}$ & 81 \\
\hline $\mathrm{CV}(\%)$ & 3,1 & 10,7 & 5,9 & 6,5 & 11,3 & \\
\hline
\end{tabular}

Em cada coluna, médias seguidas pela mesma letra não diferem entre si pelo teste de Tukey a $5 \%$ de probabilidade.

Verifica-se que praticamente todos os tratamentos foram eficientes para aumentar a germinação das sementes dos cinco lotes de mamona em relação à testemunha. Para as sementes do lote 3 , apenas o tratamento de germinação a $10^{\circ} \mathrm{C} / 30^{\circ} \mathrm{C}$ não diferiu significativamente da testemunha.
Já para o lote 4, a imersão de sementes intactas em água por 12 horas e de sementes sem carúncula em água por 24 horas e o envelhecimento acelerado forneceram resultados semelhantes aos da testemunha (Tabela 1). 
TABELA 2. Porcentagem média de plântulas normais, anormais e anormais infeccionadas e de sementes duras e mortas obtidas nos testes de germinação de sementes de cinco lotes de mamona.

\begin{tabular}{lccccc}
\hline & Lote 1 & Lote 2 & Lote 3 & Lote 4 & Lote 5 \\
\hline Plântulas normais (\%) & 74 & 66 & 74 & 78 & 59 \\
Plântulas anormais (\%) & 2 & 4 & 4 & 3 & 6 \\
Plântulas anormais infeccionadas (\%) & 2 & 2 & 2 & 2 & 4 \\
Sementes duras (\%) & 22 & 20 & 17 & 15 & 25 \\
Sementes mortas (\%) & 1 & 6 & 3 & 2 & 6 \\
\hline
\end{tabular}

Verifica-se que houve resposta diferenciada dos lotes quanto ao tratamento mais eficiente para aumentar a germinação em relação à testemunha (Tabela 1). Para o lote 1, maior germinação foi obtida com a escarificação das sementes com lixa seguida por imersão em água por $24 \mathrm{~h}$, enquanto para o lote 2 a imersão em água foi o tratamento mais indicado. Para os lotes 3 , 4 e 5 maiores valores de germinação foram obtidos com a escarificação com lixa, germinação a $10^{\circ} \mathrm{C} / 25^{\circ} \mathrm{C}$ e remoção da carúncula, respectivamente. Contudo, verifica-se que, para todos os lotes, os tratamentos que forneceram maiores valores de germinação não diferiram significativamente de outros, considerados, portanto, também eficientes para aumentar a germinação em relação à testemunha. Por exemplo, para o lote 1, a germinação das sementes da testemunha que era $74 \%$ foi elevada para $99 \%$ após o tratamento de escarificação com lixa + imersão em água por $24 \mathrm{~h}$, embora este tratamento também não tenha diferido significativamente dos tratamentos de escarificação com lixa, remoção do tegumento, remoção da carúncula, remoção da carúncula + imersão em água por 12 e 24 h, escarificação + imersão em água por $12 \mathrm{~h}$ e germinação a $10^{\circ} \mathrm{C} / 25^{\circ} \mathrm{C}$.

Portanto, é importante ressaltar que, de modo geral, considerando os cinco lotes, todos os tratamentos que contribuíram para aumentar significativamente a germinação das sementes de mamona em relação à testemunha foram, principalmente, a escarificação com lixa, a remoção da carúncula, a remoção do tegumento, a embebição em água por 12 horas de sementes escarificadas e daquelas cuja carúncula foi removida e a germinação a $10^{\circ} \mathrm{C} / 25^{\circ} \mathrm{C}$. Dentre estes, a escarificação com lixa se destaca como um dos métodos de superação da dureza tegumentar mais práticos e rápidos, especialmente quando comparado à remoção completa do tegumento e à remoção da carúncula, que envolvem procedimento tedioso e mais demorado. A eficiência da escarificação com lixa tem sido atestada por diversos autores, como constatado em sementes de Leucaena diversifolia (Schltoll.) Benth. (Bertalot e Nakagawa, 1998), Bauhinia monandra e B. ungulata (Alves et al., 2000) e Passiflora alata Dryand. (Rossetto et al., 2000), onde houve aumento expressivo na germinação das sementes escarificadas.

A embebiçãode sementes escarificadas ou sem a carúncula em água não superou os tratamentos de escarificação e de remoção do tegumento ou da carúncula, indicando que apenas a escarificação com lixa já é eficiente, sendo a embebição em água um complemento dispensável, por aumentar o tempo necessário para a aplicação do tratamento.

A remoção da carúncula foi recomendada por Oliveira et al. (2004) como método para acelerar a germinação das sementes de mamona. Estes autores embeberam sementes intactas e sem carúncula em água por 0,8 e 12 horas, utilizando sementes recém-colhidas e armazenadas por 10 meses; concluíram que a remoção da carúncula acelerou a germinação, especialmente das sementes embebidas em água por quatro horas. Já sementes recém-colhidas, embebidas em água por oito horas, tiveram atraso na germinação. Também Queiroz et al. (2004) constataram que a remoção da carúncula contribuiu para acelerar a germinação das sementes recémcolhidas, tendo efeito positivo sobre o crescimento inicial das plântulas. No presente trabalho, em geral, este método também foi eficiente para aumentar a germinação das sementes, mas não foi superior ao tratamento de escarificação (com exceção do lote 5), cujo procedimento é mais fácil e rápido (Tabela 1 ).

Em geral, verifica-se, para os cinco lotes estudados, que o tegumento limitou a absorção de água pelas sementes, pois em praticamente todos os tratamentos testados houve aumento significativo na germinação e redução na porcentagem de sementes duras (Tabela 2), aumento este que atingiu, em alguns casos, cerca de 20 pontos percentuais em relação à testemunha.

Pelos resultados de primeira contagem de germinação 
(Tabela 3), que representa a velocidade de germinação das sementes, verifica-se, para os lotes 1, 4 e 5, que praticamente todos os tratamentos aplicados às sementes contribuíram para acelerar a germinação. Nas sementes do lote 1 , cuja germinação da testemunha na data da primeira contagem foi de $61 \%$, obteve-se aumentos que variaram de 23 a 35 pontos percentuais, sendo este último verificado no tratamento escarificação com lixa + embebição em água por 24 horas. Mesmo nas sementes apenas escarificadas, sem serem submetidas a embebição, a germinação na primeira contagem foi alta (90\%), sendo 29 pontos percentuais superior à da testemunha. Nas sementes dos lotes 4 e 5 , cujas testemunhas apresentaram, respectivamente, $26 \%$ e $14 \%$ de germinação na primeira contagem, mesmo sendo todos os tratamentos superiores à testemunha, alguns se destacaram, pois permitiram que se atingisse valores iguais ou superiores a 70\%, tais como: a escarificação com lixa, a remoção da carúncula ou do tegumento, a remoção da carúncula + embebição em água por 12 e 24 horas, para ambos os lotes. Acrescentando-se, para o lote 4, a escarificação + embebição em água por 12 horas e a germinação a $10^{\circ} \mathrm{C} / 25^{\circ} \mathrm{C}$ e a $10^{\circ} \mathrm{C} / 30^{\circ} \mathrm{C}$.

TABELA 3. Primeira contagem de germinação (\%) de sementes de cinco lotes de mamona submetidas a diferentes tratamentos pré-germinativos.

\begin{tabular}{|c|c|c|c|c|c|c|}
\hline & Lote 1 & Lote 2 & Lote 3 & Lote 4 & Lote 5 & Média \\
\hline Sementes intactas(testemunha) & $61 \mathrm{~B}$ & $51 \mathrm{BC}$ & $61 \mathrm{~B}$ & $26 \mathrm{D}$ & $14 \mathrm{E}$ & 43 \\
\hline Escarificação com lixa & $90 \mathrm{~A}$ & $67 \mathrm{AB}$ & $89 \mathrm{~A}$ & $84 \mathrm{AB}$ & $73 \mathrm{~B}$ & 81 \\
\hline Remoção da carúncula & $92 \mathrm{~A}$ & $82 \mathrm{~A}$ & $89 \mathrm{~A}$ & $92 \mathrm{~A}$ & $86 \mathrm{~A}$ & 88 \\
\hline Remoção do tegumento & $94 \mathrm{~A}$ & $83 \mathrm{~A}$ & $90 \mathrm{~A}$ & $91 \mathrm{~A}$ & $86 \mathrm{~A}$ & 89 \\
\hline Imersão em água por $12 \mathrm{~h}$ & $88 \mathrm{~A}$ & $40 \mathrm{CD}$ & $69 \mathrm{~B}$ & $58 \mathrm{C}$ & $35 \mathrm{D}$ & 58 \\
\hline $\begin{array}{l}\text { Remoção da carúncula + imersão em } \\
\text { água por } 12 \mathrm{~h}\end{array}$ & $91 \mathrm{~A}$ & $68 \mathrm{AB}$ & $65 \mathrm{~B}$ & $86 \mathrm{AB}$ & $74 \mathrm{AB}$ & 77 \\
\hline $\begin{array}{l}\text { Escarificação com lixa + imersão em } \\
\text { água por } 12 \mathrm{~h}\end{array}$ & $93 \mathrm{~A}$ & $48 \mathrm{BC}$ & $75 \mathrm{AB}$ & $76 \mathrm{~B}$ & $64 \mathrm{BC}$ & 71 \\
\hline Imersão em água por $24 \mathrm{~h}$ & $84 \mathrm{~A}$ & $40 \mathrm{CD}$ & $62 \mathrm{~B}$ & $56 \mathrm{C}$ & $23 \mathrm{DE}$ & 53 \\
\hline $\begin{array}{l}\text { Remoção da carúncula + imersão em } \\
\text { água por } 24 \mathrm{~h}\end{array}$ & $90 \mathrm{~A}$ & $66 \mathrm{AB}$ & $72 \mathrm{~B}$ & $72 \mathrm{~B}$ & $73 \mathrm{~B}$ & 75 \\
\hline $\begin{array}{l}\text { Escarificação com lixa + imersão em } \\
\text { água por } 24 \mathrm{~h}\end{array}$ & $96 \mathrm{~A}$ & $35 \mathrm{CD}$ & $72 \mathrm{~B}$ & $68 \mathrm{BC}$ & $56 \mathrm{C}$ & 65 \\
\hline Germinação a $10^{\circ} \mathrm{C} / 25^{\circ} \mathrm{C}$ & $91 \mathrm{~A}$ & $68 \mathrm{AB}$ & $62 \mathrm{~B}$ & $89 \mathrm{~A}$ & $47 \mathrm{C}$ & 71 \\
\hline Germinação a $10^{\circ} \mathrm{C} / 30^{\circ} \mathrm{C}$ & $86 \mathrm{~A}$ & $67 \mathrm{AB}$ & $70 \mathrm{~B}$ & $88 \mathrm{AB}$ & $50 \mathrm{C}$ & 72 \\
\hline Envelhecimento acelerado & $85 \mathrm{~A}$ & $24 \mathrm{D}$ & $65 \mathrm{~B}$ & $50 \mathrm{C}$ & $27 \mathrm{DE}$ & 50 \\
\hline $\mathrm{CV}(\%)$ & 2,7 & 15,8 & 8,4 & 12,4 & 13,7 & \\
\hline
\end{tabular}

Em cada coluna, médias seguidas pela mesma letra não diferem entre si pelo teste de Tukey a 5\% de probabilidade.

Para os lotes 2 e 3 (Tabela 3), em geral, os tratamentos mais eficientes para acelerar a germinação foram apenas a escarificação com lixa e a remoção da carúncula ou do tegumento. Assim, nestes lotes, verifica-se que nem todos os tratamentos que haviam sido eficientes para aumentar a porcentagem final de germinação (Tabela 1 ) foram adequados para acelerar a germinação (Tabela 3).

A remoção da carúncula foi considerada por Oliveira et al. (2004) um método adequado para aumentar a velocidade de germinação das sementes de mamona, visto que a micrópila fica livre para que a raiz primária possa ser exposta. Já quando se remove totalmente o tegumento, a velocidade de germinação é aumentada pelo fato de não haver barreira para a hidratação dos tecidos da semente nem para o crescimento do embrião; contudo, pode haver dano por embebição rápida e aumento da ocorrência de microorganismos. Estes 
aspectos não foram observados no presente trabalho, uma vez que a proporção de sementes e plântulas infeccionadas nos tratamentos que envolveram a remoção do tegumento foi semelhante à obtida nos tratamentos de escarificação, imersão em água e germinação a $10^{\circ} \mathrm{C} / 25^{\circ} \mathrm{C}$. Vale ressaltar que, a remoção da carúncula e do tegumento são tratamentos mais demorados por terem que ser aplicados a cada semente individualmente, não podendo se desconsiderar a dificuldade de execução sem danos ao embrião das sementes. Além disso, são métodos inviáveis para grandes volumes de sementes, uma vez que são realizados manualmente com o auxílio de um estilete ou bisturi. Já a escarificação com lixa é mais fácil de ser aplicada, especialmente quando se trata de grande quantidade de sementes.

Em síntese, verifica-se que o uso de tratamentos pré-germinativos em sementes de mamona foi eficiente para acelerar e aumentar a germinação em condições de laboratório.

\section{CONCLUSÕES}

Tratamentos pré-germinativos contribuem para aumentar a porcentagem de germinação das sementes de mamona.

Os tratamentos mais eficientes para acelerar a germinação das sementes são a escarificação com lixa e a remoção da carúncula ou de todo o tegumento.

\section{REFERÊNCIAS}

ALVES, M.C.S.; MEDEIROS-FILHO, S.; ANDRADENETO, M. \& TEÓFILO, E.M. Superação da dormência em sementes de Bauhinia monandra Kurz e B. ungulata L. - Caesalpinioideae. Revista Brasileira de Sementes, v.22, n.2, p.139-144, 2000.

BERTALOT, M.J.A.; NAKAGAWA, J. Superação da dormência em semente de Leucaena diversifolia (Schlecht.) Bentham K156. Revista Brasileira de Sementes, v.20, n.1, p.39-42, 1998.

BEWLEY, J.D.; BLACK, M. Seeds: physiology of development and germination. 2.ed. New York: PLENUM PRESS, 1994. 445p.

BRASIL. Ministério da Agricultura e Reforma Agrária. Regras para análise de sementes. Brasília, DF: CLAV/ DNDV/SNDA/MA, 1992. 365p.

DFASP. Departamento Federal de Agricultura de São Paulo. Disponível em: <http://www.dfasp.gov.br/sefag_vegetal/doc/ legislacao/anexo vii da instrucao normativa 25 de 16 12-2005.pdf>. Acesso em: 28 ago.2007.

FONSECA, N.R.; MYCZKOWSKI, M.L.; PRIOR, M.; SÁ, R.O.; NAKAGAWA, J.; CAVARIANI, C.; ZANOTTO, M.D. Testes de avaliação da viabilidade e do vigor em sementes de mamona. In: CONGRESSO BRASILEIRO DE MAMONA - Energia e Sustentabilidade, 1., Campina Grande, 23/26 nov. 2004. Anais... Campina Grande: Embrapa Algodão, 2004. p.07-12.

LAGO, A.A.; ZINK, E.; RAZERA, L.F.; BANZATTO, N.V.; SAVY FILHO, A. Dormência em sementes de três cultivares de mamona . Bragantia, v.38, p-XLI-XLIV, 1979.

LIMA, D.; GARCIA, L.C. Avaliação de métodos para o teste de germinação em sementes de Acacia mangium Willd. Revista Brasileira de Sementes, v.18, n.2, p.180-185, 1996.

LUCENA, A.M.A.; SEVERINO, L.S.; COSTA, F.X.; GUIMARÃES, M.B.; BELTRÃO, N.E.M.; CARDOSO, G.D. Germinação de sementes de mamona tratadas com giberelina $\left(\mathrm{GA}_{3}\right)$. In: CONGRESSO BRASILEIRO DE MAMONA - Energia e Sustentabilidade, 1., 2004, Campina Grande. Anais... Campina Grande: Embrapa Algodão, 2004. p.84-87.

MARCOS-FILHO, J. Fisiologia de sementes de plantas cultivadas. Piracicaba: FEALQ, 2005. 495p.

MARCOS-FILHO, J. Teste de envelhecimento acelerado. In: KRZYZANOWSKI, F.C.; VIEIRA, R.D.; FRANÇA NETO, J.B.. (Ed.). Vigor de sementes: conceitos e testes. Londrina: ABRATES, 1999. p.3-1 - 3-21.

OLIVEIRA, A.B.; QUEIROZ, J.A.; MENEZES, C.H.S.G.; CARTAXO, W.V. \& SUASSUNA, N.D. Efeito do tempo de embebição em água e remoção da carúncula na germinação de sementes de mamona (Ricinus communis L.). In: CONGRESSO BRASILEIRO DE MAMONA - Energia e Sustentabilidade, 1., 2004, Campina Grande. Anais... Campina Grande: Embrapa Algodão, 2004. p.123-128.

PEREZ, S.C.J.G.A. Envoltórios. In: FERRREIRA, A.G.; BORGHETTI, F. (Org.). Germinação do básico ao palicado. Porto Alegre: Artmed, 2004. p.125-134.

PEREZ, S.C.J.G.A.; FANTI, S.C.; CASALI, C.A. Dormancy break and light quality effects on seed germination of Peltophorum dubium. Revista Árvore, v.23, p.131-137, 1999.

QUEIROZ, J.A.; OLIVEIRA, A.B.; MENESES, C.H.S.G.; CARTAXO, W.V.; SUASSUNA, N.D. Efeito da remoção da carúncula, tratamento químico e tempo de armazenamento na germinação de sementes de mamona (Ricinus communis L.). 
In: CONGRESSO BRASILEIRO DE MAMONA - Energia e Sustentabilidade, 1., 2004, Campina Grande. Anais... Campina Grande: Embrapa Algodão, 2004. p.91-96.

ROSSETTO,C.A.V.;CONEGLIAN, R.C.C.; NAKAGAWA, J.; SHIMIZU, M.K.; MARIN, B.A. Germinação de sementes de maracujá-doce (Passiflora alata Dryand.) em função de tratamento pré-germinativo. Revista Brasileira de Sementes, v.22, n.1, p.247-252, 2000.

SAS. SAS/STAT user's guide. Version 6,4 ed. SAS Cary, NC, Institute Inc, 1989. 